\title{
Translation Theories and Translating Assamese Texts
}

\author{
Manjeet Baruah
}

\begin{abstract}
The paper is divided into two broad sections. The first section examines the changing focus of translation theories worldwide, especially in the last three decades, and the facility that the newer developments in translation theories have provided in translating texts in multi-lingual societies. It will be shown that vis-à-vis the old school of linguistic equivalence, the shifts into the fields of power discourse (i.e. politics of translation) and translation have provided the framework for approaching the praxis of translation in multilingual societies more fruitfully. The second section of the paper comprises two case studies of specific forms of writing in the Assamese language, viz. (a) Bezbarua and colloquial aesthetics, and (b) Indira (Mamoni Raisom) Goswami and multiple language variant textual structure. The two textual methods will be discussed vis-à-vis the problematic of their respective translations and in the context of the theoretical outline drawn in the first section. The objective of the exercise is twofold, viz. (a) to highlight and explore the potentials in applied translation vis-à-vis languages of North East India and (b) to emphasize the peculiarities in translating texts from or into languages and cultures of North East India.
\end{abstract}

Keywords: translation theory, South Asia, North East India, Laksminath Bezbarua, Indira (Mamoni) Raisom Goswami, Assamese literature, modern Indian language, ideology, textual structure.

\section{Section I}

In this section, the attempt is to draw a broad outline of the debates in translation theories, especially in the 20th century, 
and create the platform for the discussion on translation visà-vis languages of north east India (with Assamese texts as the illustration) in the subsequent section. Between the $1950 \mathrm{~s} / 60 \mathrm{~s}$ and 1980 s/90s, translation theories have undergone paradigm shift. The fundamental component of the shift has been the transition from models of praxis to models of analysis. For example, one of the most distinct features of translation debates in the 1950s/60s was the question of linguistic equivalence, i.e. how to arrive at linguistic equivalence between the source language $(S L)$ and target language ( $\mathrm{TL})$. One of the underlying factors of the debate was the assumption of universal language. It was precisely because of the assumption of universal language that, irrespective of the positions that theorists held, that linguistic equivalence between the $S L$ and $T L$ was possible was never questioned.

On the issue of linguistic equivalence and how to arrive at it between the $S L$ and $T L$, one of the most comprehensive frameworks was perhaps offered by Nida (Nida, 1964). Nida not only focused on the possibility of equivalence, but also developed a model based on Chomsky's system of deep structure-surface structure of language vis-à-vis SL-TL relation. The fundamental argument of Nida was that from the surface structure of the $\mathrm{SL}$, the translator has to move into its deep structure, and then find the equivalent of the SL deep structure in the deep structure of the TL. Thereafter, the TL can be developed into its surface structure. Nida argued that through this process, a scientific equivalence between the SL and TL can be arrived at. Nida also advocated that translation should be of dynamic equivalence and not formal equivalence and that through the above process of deep structure-surface structure inter-language relation, dynamic equivalence can be arrived at. The basic thrust in Nida's argument, i.e. of dynamic equivalence, can be traced back to earlier periods as well. However, what was unique about his model was that it offered a systematic mechanism, unlike the previous theories, of how to achieve dynamic equivalence between SL and TL while translating. For example, a simple illustration of the complex process of dynamic equivalence can be shown in translation of 
proverbs. Going by Nida's argument, a proverb in SL would need to be broken down into its deep structure, and then through its deep structure equivalence in the $T L$, the surface structure linguistic equivalence can be arrived at in the TL. Proverbs are notable illustration of Nida's argument on two counts. On the one hand, it negates the notion of untranslatability, i.e. something as peculiar to locale as proverbs cannot be translated. On the other hand, it highlights how meaning of proverbs cannot be translated in literal method. The specifics of linguistic expression of the proverb in the SL and TL may vary. But in the process, their meaning would remain the same. Noam Chomsky's theory of Syntax and generative grammar was not, nor was it intended to be, a theory of Translation. In fact, Chomsky cautioned against its appropriation (Gentzler, 2010: 46-64)

It is evident that a founding principle of the Nida's model was how to translate. Nida himself was a practicing translator, involved in translation of the Bible. His objective was that the Bible should reach the maximum people in the world. But this intent behind translation also highlights another point, viz. the why behind the how to translate. In other words, if Nida demonstrated that through the paradigm and method of dynamic equivalence, the problem of untranslatability can be overcome, it was because it was necessary for him that the Bible is translatable in any language. Nida's approach was evidently influenced by the reigning approach of the times, namely structuralism. Therefore, if one returns to the example of proverbs, there is the underlying assumption that its meaning in the deep structures of the SL and TL can remain same due to the reality of universal language. But where Nida was different was that despite his assumption of universal language and a structuralist method of arriving at it, he took into account the problem of linguistic differences and that the problem can only be addressed "dynamically" and not formally or literally. Behind these theoretical explorations, his politics of religion was of crucial importance.

It was such cases as Nida's, i.e. exposing the often hidden 
or invisible reality of motive/objective behind translation, and how it shapes theoretical explorations, that came to be foregrounded in the 1980s. This foregrounding became a paradigm shift in translation, pushing the domain from translation to translation studies, i.e. from praxis to studies. This shift has come to be called the 'cultural turn in translation', traced to a series of new studies since the late 1970s and 1980s. The primary shift that took place through these studies was that translation debates were no longer in terms of how to translate; rather they were in terms of the three factors of who, why and when vis-à-vis any translation. How to translate, in fact, became now a corollary of the above three factors of who translates, why it is translated and when it is translated. In other words, vis-à-vis the text, it is the context that became more crucial in explaining or comprehending a translation. Now the understanding was that once the context is explained or can be determined, how to translate can also be arrived at. This shift, as well known today, came to be termed "cultural turn in translation". What it meant was that it was not language and its structure wherein the meaning of translation can be located. The meaning of translation was in the socio-political and cultural context (or specifics) of translation which involved questions of who, why and when rather than how.

'Cultural turn in translation' was marked by multiplicity in approaches vis-à-vis the relation between translation and its context. For example, the polysystem model (Toury: 1995) emphasized the importance of target culture in explaining the nature of translation. The model followed a binary classification of target (language) culture in terms of weak and strong target cultures, and argued that when the target culture is weak, translations are more naturalized or domesticated in the $\mathrm{TL}$, whereas when the target culture is strong, the foreignness of the SL text in the translation remains visibly evident. In other words, a weak TL culture tends to naturalise translations in its own repertoire (and gives the appearance of being its own cultural production rather than as one originating elsewhere) while a strong TL culture does not suffer such anxieties and therefore 
does not hesitate to highlight that the translated text is not its own cultural production, but has come from another culture into its now expanded repertoire.

Despite the apparent similarity of the model to the 18th-19th century nationalist approach to translation in Europe, especially in France and Germany (Venuti: 2004) wherein foreignness of SL culture in translation was argued to highlight the unique national character of the $T L$, the polysystem model is fundamentally different in its principles from it. The main difference is that the polysystem model is not premised on one particular assumption of politics. On the contrary, it leaves open a space for context specific politics to be incorporated within the larger framework of weak-strong binary in target culture. But one of the main problems of the polysystem model is how to ascertain whether a culture is weak or strong. It may be argued that the strength or weakness of TL culture could be ascertained by its very practice of translation. But such an approach only explains the action (nature of translation practiced), not what produces the action itself. To use a South Asian illustration of the problem, the pre-colonial transcreations of the epic in different languages, though borrowed from the "cosmopolitan" Sanskrit literary world to which they traced their connected histories, nevertheless claimed their difference overtly from that "cosmopolitan" world through their very act of transcreation (and not "translation"). The problem here is twofold. On the one hand, how would one ascertain the strength or weakness of the TL culture in such cases of transcreation which stands outside the foreign-natural act/nature of translation. In other words, how does one explain transcreation through the polysystem model. On the other hand, transcreations also raise an additional question, i.e. how meaningful are binaries such as cosmopolitan and vernacular, or great and little traditions etc. When seen from this question, the polysystem model once again falls short of explaining a historical phenomenon of literary culture found widely in pre-colonial South Asia.

In contrast to the polysystem model and its assumptions 
of strong or weak TL culture, therefore, there are approaches which highlight the critical significance of ideology or ideological relation between $S L$ and $T L$ to explain the nature of a given translation. For example, in the works of Lefevere (Lefevere, 1993), the discussion is more concentrated on the historical or sociopolitical context of the target culture or in the relation between the source and target cultures rather than on the linguistic or grammatical aspects of the SL and TL in question. Lefevere argues that peculiarities of grammar and language do not sufficiently explain the textual features in translation. The broader argument he makes is that while translating, which is a practice, linguistic choices are exercised by the translator. These choices are not necessarily pre-given in languages per se. These choices are conditioned by the context and objective of the translator/ translation. It may be interesting to note here the remarks of Levi Strauss vis-à-vis the significance of totems in this regard (Strauss, 1982). Strauss argued that totems are interfaces that translate nature to human society and vice versa. Thus, if the argument is carried forward, one can present a case that totems may be seen as codes of translation. Such an approach to translation opens a tremendous space for ethnographic study vis-à-vis translation. However, we will return to this point later in the discussion.

With regard to the role of ideology, there are three major approaches or models of the period that needs to be emphasized. Each of them takes the study and practice of translation away from the linguistic orientation that the field predominantly had until the 1960s. One of them has been the model of linguistic discourse analysis. Under this model, a text is analyzed in terms of the three linguistic registers of field, tone and mode (Baker, 1992), in which field refers to the content, tone to who is communicating through the text and mode to the medium of communication, i.e. oral or written. The model, based on Halliday's framework, compares the text in its SL version and TL version based on the three linguistic registers, and indicates the changes or character that they assume in their respective conditions. One of the fundamental principles of this model is that it is not language per se but the use of language 
in given contexts that is more important. It is given usage of language that explains the character of a text and its relation to the context. It is evident here that though based on study of language and its use, the model fundamentally differs from the concept of linguistic equivalence. Among others, one of the basic differences is that unlike the concept of linguistic equivalence, it is not based on any assumption of universal language; thus, the emphasis on usage of language as the key to understanding or translating meaning in text. Needless to point out that usage of language is located in the ideological use of language rather than merely the linguistic features of a given language.

Another major breakthrough in the field of translation studies came in the late 1980s and early 1990s through the translation debates that Subaltern Studies initiated in India (Spivak, Paul, 2007). Subaltern Studies sought to interrogate and engage with the voices of the marginal which, it claimed, are frequently lost in textual sources or written materials. It is because language and communicating through language is mediated through the relations of unequal power. Since written language bears the hegemony of the powerful in a society, therefore, it fails to carry or communicate the voices of the marginal which inhabits that society. Spivak's translation of Mahasweta Devi's fiction is notable in this regard. The challenge that Spivak, as a translator, poses can be stated as when translation is taking place into a dominant language in any give social context, what are the possibilities of retaining the message of protest of the dominated against the dominant within the linguistic or narrative framework of the translated text. The translation strategy that Spivak uses in this regard has two aspects. At one level, Spivak retains words/ syntax (in italics) of the (dominated) SL in the (dominant) TL. At another level, sentences/words/passages will be put in italics in the TL which, in the $S L$, is not placed in italics. The objective in the second case is to indicate to the reader that the italicized carries meaning or message that the reader needs to take note of. Therefore, Spivak makes an active intervention in the translation and in the process adds new dimensions to the interpretation 
of the SL text and production of culture in general. From the perspective of Subaltern Studies, this nature of intervention is considered as necessary for three reasons, viz. (a) to prevent the cultural appropriation of the dominated by the dominant, (b) to emphasize that the dominant culture (in this case language and narrative of text) lacks the capacity to communicate the culture of the dominated, and (c) through the use of italics (as already noted) and making the reading of the translation uneven, the attention of the reader can be drawn to the deeper context of power relation in culture and production of culture.

The act of active intervention that a translator can and needs to make in the larger context of production of culture has come to be most significantly advocated in the 1990s by Lawrence Venuti (Venuti, 1992). He has put the debate in the framework of visibility vs. invisibility of translator. Venuti's argument rests primarily on two factors, viz. ideology of translator and translator communicating with readers beyond the mediation of the author of the SL text. On the question of ideology and translator, he points out that every translation is premised on ideological choices and ideological acts. Therefore, if a translation has to be understood or explained, it is necessary that the ideological foundations of the translation needs to be taken into consideration. In this case, the translator's ideology assumes critical significance. Without explaining the translator's role, the translation too cannot be comprehended. But Venuti makes a further point as well, which follows from the above point. He argues that precisely because translator plays a critical role in the production of meaning in a given translation, it is necessary that s/he communicates with the reader beyond the author of the SL text. Translation is an ideological reproduction of the SL text. Therefore, the meaning in the translation goes beyond the meaning in the SL text. As a result, a translator should seek to highlight the role that $\mathrm{s} /$ he plays in the reproduction of the original that the translation is. In other words, a translator has to make himself or herself visible.

The above position challenged one the fundamental 
premises of form in TL text. Translation theories in the West have historically favoured meaning based translation to word based translation. In other words, compared to word-for-word translation, the emphasis needs to be on translation of meaning from the SL text to the TL text. Thus, translation theories focused on paraphrase or dynamic equivalence vis-à-vis metaphrase or formal equivalence. The critical point here is the relation between form and readability in translation. Paraphrase or dynamic equivalence places emphasis on naturalizing or domesticating of SL in TL text. The deep structure-surface structure process is nothing but a mechanism to arrive at the naturalized form of the SL text in the TL. However, in stark contrast to the above approach, the paradigm of visibility vs. invisibility of translator argues that naturalized form masks the deeper ideological meaning in translation, and therefore it needs to be shed. In other words, narrative realism is to be avoided in translation. To be noted here is that Spivak's use of italics in the translation also forms part of this paradigm of translator's visibility, seeking to communicate with the reader beyond the role of the author of the original. (It may also be noted that challenging narrative realism to indicate the ideological construct of art was at the root of neo realist cinema of post World War II Europe.)

\section{Section II}

In the previous section, we have tried to draw a broad outline of the 'paradigm shift' that debates in translation have undergone in the course of half a century in Europe, especially after World War II. In this section, we will try and situate the question of situating translation of literary productions in the Assamese language in this above debate on translation and translation theory. As already noted, two case studies of specific forms of writing in Assamese language, viz. (a) Bezbarua and colloquial aesthetics, and (b) Mamoni Raisom Goswami and multiple language variant textual structure will be taken into consideration in this regard. 
The writings of Lakhminath Bezbarua (1868-1938) are taken as the first example (Baruah, 2010). The particularity of Bezbarua's literary aesthetic was in the way the oral and textual narrative elements could come together. If aesthetic is approached as a structure, it becomes evident that two sets of relations were central to the aesthetic structure of Bezbarua's writings, namely (a) language-narration-narrator/author and (b) plot-narrationnarrator/author.

One of the most distinct features of Bezbarua's aesthetic structure is the simultaneity of realism and traditional anti-realism that could be achieved through the relation of language, narration and narrator/author. The difference in the structure of language that Bezbarua used comes into sharper relief when compared to other writers, either contemporary or especially those since 1940 s. Bezbarua did not maintain any significant distinction between the language of the characters (conversations, first person) and that of (third person) narration. But unlike many other writers, he did not make his characters speak in textual Assamese, or in the written form of the language. Therefore, both the characters and the narration could proceed based generally on colloquial Assamese of the eastern part (upon which the Sibsagar variant of Assamese language is based) of Assam. Another author (as discussed later) who made extensive use of colloquial language in conversations among the characters was Indira (Mamoni Raisom) Goswami. However, in her writings, the language of narration was different from that of conversation among the characters. The textual form of Assamese exists in her writings as the referent against which the language of conversations operates and gives meaning to the text.

In terms of aesthetic structure, the method of Bezbarua with regard to the relation between language and narration made the narrator/author a far greater distinct a factor of the text. More appropriately, the narrator/author did not remain a covert textual factor but as an overt textual factor. Further, it is necessary to mention here that Bezbarua's use of traditional anti-realism was also evident in the impersonal relation between narration 
and narrator. The narrator would distinctly be different from the narration. The narrator is not part of the narration and the world of the narration. In that, it was closer to the mode of tale. In the case of Bezbarua, it was tale that was situated in the genre of satire.

However, it would be incorrect to consider his aesthetic as non-modern. It was modern in nature not only because he worked through modern narrative forms such as short stories or novels, or because his fictions existed as mass consumed 'books' and not 'texts', but because his aesthetic was also to heighten the effect of his (a) nationalist ideology and (b) to expose the reality of the process of modernity that the society was experiencing during the period. A liberal nationalist in his political ideology, Bezbarua made language, narration and narrator/author distinct and different from each other within the aesthetic structure. His aesthetic did not deny differences; rather he developed an aesthetic structure to accommodate that social reality, and through it, create a nationalist construct of 'Assamese people'. In other words, his aesthetic indicated acutely both the modern context and it's (both the society and the aesthetic) location in that modern context and that it was precisely that location that allowed it its distinct character as an aesthetic.

The other issue that gets highlighted in/through such use of oral short narratives is that it is not only that a literary narrative structure is borrowing from oral culture but that it is also possible to invent oral narratives, and thereby forms of oral culture, through such literary aesthetic. Unlike in other kinds of literary aesthetics used in Assamese literature where the textual is generally used as referent for the oral, in Bezbarua's case, it would be difficult to locate any referent, whether in the textual or in the oral, in the structure of the narrative. All the constituents of the structure exist as referents for each other and it is that exchange that gives meaning to the narrative. Therefore, it is quite possible to argue that Bezbarua's aesthetic structure could also invent oral narratives within itself by situating it in specific relation to the various elements of the narrative structure. In other 
words, it shows that oral forms could be invented through literary structures as well.

The second writer whose writings have made a critical difference to literary aesthetic in modern Assamese fiction is Indira (Mamoni Raisom) Goswami (1942-2011). Her writings brought to the fore the subject of 'women' in modern Assamese literature. The structural characteristics of her fiction have already been indicated in the preceding discussion. What needs to be emphasized in this context is the role of direct and indirect speech in the construction of 'people' in or through the literary aesthetic. The facility of direct and indirect speech is a modern grammatical mechanism in Assamese literature. In all pre-modern Assamese literature, the distinction between the narration of the narrator and conversation among the characters of the plot was descriptively indicated (i.e. the narrator would say that the following is a conversation between the characters). ${ }^{1}$ The difference that the facility of direct and indirect speech introduced was that it was no longer necessary to describe the nature or progression of plot; rather it could be achieved through the structure of the language itself. But if the significance of this facility is seen in reference to the construction of identity or 'people' through the narrative itself, it found its most effective usage in the fictions of Mamoni Raisom. Her fictions indicated that Assamese identity was not a homogenous phenomenon. And the exploration and demonstration of the fact was carried out through the use of this grammatical facility.

In her fictions, people of different caste or class or region or gender would speak differently. But, as already noted, her fictions would not lack a referent to indicate that the diversity that the text exhibits in the social nature of the characters exists within the larger category of Assamese identity. The language of narrator's narration (in the third person) of the plot takes place in the Sibsagar variant of the Assamese language. This variant exists as the indicator of the larger Assamese identity within which the diversity exists. The other aspect in this character of the narrative 
structure is that it highlights the relation of the various social groups within the larger Assamese identity (as part of the plot) and it also highlights the relation that the author/narrator seeks to establish with the fact of social stratification and interaction thereof. In other words, her different language variant exists as a marker of her ideological position since it is the narration of the plot that is giving a character to the plot itself. In the process, in the space of the text, both the constituents and the constituted of the 'people' come to be accommodated.

Further, it is important to note that if the fictions of Mamoni Raisom are assessed in terms of issues that are taken up in her writings, women emerge as a focal point of that engagement or exploration of society. But if her texts are analysed in terms of its narrative structure, what emerges as more fundamental is the engagement with the construction of identity (Assamese people) through or in literature. This difference is central to analyzing her whether as a woman writer or a feminist writer. In this context, locale of the plot has played a crucial role.

Mamoni Raisom has been one of the few writers in Assamese literature whose major works are based on locales both within and without Assam. Among her major novels which are based on locales outside Assam are Senabor Strot, 1971 (The Currents of the Chenab, Kashmir), Nellkanthi Braj, 1976 (The Blue Necked Braja, Vrindavan), Ahiron, 1980 (Ahiron, Madhya Pradesh), Mamore Dhara Taruwal, 1980 (The Rusted Sword, Uttar Pradesh) and Tez Aru Dhulire Dhusarita Pristha, 1990 (Pages Stained in Dust and Blood, Delhi). The critical difference that locale made in her fictions is evident from the fact that in fictions based outside Assam, the mechanism of direct-indirect speech only has a functional rather than any conceptual value. Unlike as in the case of fictions based in Assam, the role of direct and indirect speech in the above mentioned novels is only to indicate a conversation rather than to indicate any process of identity formation. Therefore, though in most of her writings the focus on women is paramount, the meaning of/in the narrative structures varies based on the 
locales in which the plot of the narrative is based. In the case of plots that are based outside Assam, the issue emerges as both the text and the subtext. But when the locale has been within Assam, the meaning of the text and the subtext could differ, based on which one (issue/topic or narrative structure) is considered the text and the subtext.

It is not to argue that this principle applies to all her fictions. Two notable exceptions in this regard are Mamore Dhara Taruwal (The Rusted Sword) and Datal Hantir Une Khowa Howda (The Moth Eaten Howdah). In Mamore Dhara Taruwal, the character of Narayani, a Dalit woman labourer, is torn between her identity as a Dalit labourer and as a woman. Even though she fights for her right over her body and sexuality against control by the community, she herself remains unsure to what extent the distinction of the individual and community could be possible or realizable. Similarly, in Datal Hantir Une Khowa Howda, relation of power and the conflict between the religious head/landlord and the lower caste/landless peasants and the dilemma of the widows caught up in between is brought out through the very nature of the topic and not through that of language and its variants. The two novels highlights that locale under all conditions need not indicate social stratification through linguistic structure and thereby point to the larger context of identity that the text is engaging with. Whether in the case of Narayani in Mamore Dhara Taruwal or in the case of the widows in Datal Hantir Une Khowa Howdah, that gender is not a homogenous construct in itself is brought out by the nature of the issue/topic rather than any component of the narrative structure. The plot or the language or its grammatical usage merely fulfills the conditions that the topic creates for/in the text.

Does the distinction that specificity of locale introduces in her texts help us when considering the ideological orientation of Mamoni Raisom's writings? The answer is yes. It is possible to identify two different results that the specificity of locale introduces to her liberal humanist position. In her fictions based 
on locale outside Assam, the engagement with the fact of social stratification (along caste, class or gender lines) in society has been in terms of an abstract idea of 'human'. The pathos that mark the life of the characters and the progression in the plot emerge from the idea that the category of 'human' and all its humaneness needs to be restored and therein only lies the solution to social stratification and the conflicts that emerges from it in society. In other words, it is humanity that can bring solution to the problem of social stratification rather than any revolution. But in the case of fictions where the locale has been within Assam, the basic problem that the texts seek to engage with is the challenge not only in the restoration of the 'human' but also in the restoration of its political face, namely the Assamese identity. If a political identity lacks humanity, the identity too would lack ability to accommodate diversity. The difference between the two situations is evident. Whereas in the former, the 'human' is an abstract idea, in the latter, it exists as a far more political idea. Also, whereas in the former, (with the exception of novels like Mamore Dhara Taruwal) the treatment of women characters in terms of issue/topic and narrative structure has little distinction, in the latter, there is a fundamental difference. The difference is that women, in the latter, are no longer only women but are also part of the larger process of national identity formation. And in the texts, the difference becomes evident in the split of meaning between the issue/topic and structure of the narrative, something largely absent in the former. The difference between the two cases is also evident in that whereas in the former, social stratification is emphasized, in the latter social differences (i.e. 'local' vis-à-vis 'national') are also emphasized along with social stratification.

One of the central contributions of Mamoni Raisom's writings in modern Assamese fiction has been that it made possible the split of meaning between the issue/topic and structure of the narrative in a given text. In other words, meaning was distributed among the various elements of the textual structure. There are three dimensions to the significance in this regard. Firstly, it facilitated correcting a rupture that texts, or more 
appropriately, narrative structures in Assamese fiction had faced in the twentieth century. One of the major problematic that fiction had faced, especially since the 1940s, was how to establish the legitimacy of Assamese identity vis-à-vis social/ethnic differences and social stratification. Most texts that attempted to address differences of ethnicity, race or class among the people who constituted Assamese identity, tried to work through a narrative structure in which characters shed the specificity of their social origin. They neither speak their own language variant nor the plot aimed to emphasize that they are different. The differences would only be described by the author in the third person narrative. Therefore, differences generally played a functional role in the text than any conceptual role. This conscious role allotted by the author to differences of being merely functional rather than being conceptual exposed the ruptures in the texts, that what could be conceptual existed only as functional in the narrative structure, for example, as in Birinchi Barua's Seuji Pator Kahini (a novel based on the multi-cultural social world of the tea plantations of Assam). Mamoni Raisom's writings helped overcome this dichotomy or rupture in a major way. It was no longer necessary to provide differences only a functional role. Even by providing it a conceptual role in the structure of the text, the larger argument of the validity of the Assamese identity could still be made. And a split in meaning between the issue/topic of the text and the structure of the narrative could facilitate this process. As a result, it was also no longer necessary that narrative structure merely fulfills the conditions that the topic of the text creates. The meaning of text and subtext could vary, given which one between the issue/topic of the text or its narrative structure is taken as the text and the subtext. ${ }^{2}$

The second significance of her writings, related to the preceding point, has been that it opened an enormous space for the exploration of the category of women through/in literature. Women's literature need not be only about women. A textual structure was now available through which multiple identities, including gender, could be addressed simultaneously without 
creating any textual ruptures. By the 1980s, Mamoni Raisom's literary aesthetic was well in place. And since then, it had emerged as one of the most distinct literary aesthetic not only on women's issues (written by women or men) but also on various other kinds of issues.

The third significance of her writings is the nature of relation between the oral and the textual that was used or established in the text, especially in comparison to the writings of Lakhminath Bezbarua. The nature of this relation in their writings can be seen at two levels. Firstly, whereas in the case of Bezbarua, there was a constant attempt to dilute the difference between the oral and the textual in the structure of the text to give expression to their respective constructs of 'people', in the case of Goswami, the difference between the oral and the textual was retained through the mechanism of direct and indirect speech and the distinction was used to highlight the multiplicity rather than homogeneity within any construct of 'people' (including gender) in the Assamese society.

Secondly, with regard to Bezbarua and Mamoni Raisom, it needs to be mentioned that neither author tried to undermine social differences and social stratification within the Assamese identity through their plot and characterization. The critical difference here is that whereas Bezbarua, with his peculiar mix of the oral and the textual and with the overwhelming role retained for narration, overwhelmed the differences and/or conflicts within the category of his 'people' which the characters, plot and narrator symbolically represented, while in Mamoni Raisom, the author/narrator existing as only a referent did not overwhelm differences and/or conflicts within the larger identity. The relation between plot, narrator and narration played a crucial role in this regard. In Bezbarua's writing, as has already been highlighted, narration was more than the sum of narrator and plot. Bezbarua's fictions, especially short stories, had two conclusions, first where the narration of the plot ends (whether or not the problem that the plot addresses concludes or not) and second with the 
concluding oral short narrative where, and through which, the narrator/author concludes the narration of the entire narrative by stating that the narration finally ends. The use of such oral forms (borrowed from tales) as concluding devises is both important and interesting because they not only constitute a particular modern literary aesthetic but also because they expose the fact that within the structure of the aesthetic, the plot, the narration and the narrator/author are three distinct constituting elements related to each other in a certain mode. It was this character of the narration that made possible to retain the totality of meaning within the aesthetic. Therefore, whereas in Bezbarua's writings, there is no split of meaning within the text, in the case of Mamoni Raisom, the split of meaning between the issue/topic of text and its narrative structure is evident. In Mamoni Raisom's fictions, the narration and the narrative end with the end of the plot as well.

\section{The Challenge of Translation}

Is it possible to argue that the two cases discussed above are cases of embedded translation? It is evident that in either case, the elements of the textual structure share (a) multiple forms or layers of relations with each other, and (b) these relations are dynamic in nature. In the factor (a), respective meanings are translated into each other and this constitutes the dynamic fundamental (i.e. factor (b)) of the relations. Whether it is in terms of voice(s) and meaning thereof, or in terms of use of language, or in terms of narration and narrative, or in terms of ideology or that of text and context, it is amply evident that meaning is located at the intersections of relations among the textual elements, one attempting to translate the meaning of the other(s).

Therefore, the question is where do we situate translation of such texts in the existing debate on translation and translation theory as outlined in Section I? Secondly, is it possible to posit that Indian literature (Assamese literature in this case) can play a crucial role in making fundamental breakthroughs in the future direction of translation debate? That the principle of semantic transference 
of meaning through translation cannot be a translation methodology in this case is already evident. This is despite the fact that in South Asia, the framework of semantic transference of meaning has been based not on SL and TL equivalents as in the West but, as noted in Section I, on SL culture and TL culture, a process facilitated by the simultaneity and difference within South Asian culture formations. Therefore, the methodological option available for translation of such texts is the generative approach (which encompasses the perspectives of the "cultural turn in translation"). In this approach, the basic assumption is that translations reproduce the meaning of the SL text in its own given context. As a result, translations generate their own meanings of the $S L$ text rather than merely making available the meaning of the SL text in another language. Without entering into the debate on meta-text or total text (Fitch: 1988), it is evident that dynamic fundamental is basic to the generative approach in translation. From the discussion in Section I, it is also evident that the generative approach has come to constitute one of the most influential approaches to the study of translation since the 1980s.

But in contrast to the debates on 'translation studies', the challenge while translating under the rubric of generative approach is/will be methodological. In other words, how does one develop a methodological framework of translation praxis that can accommodate SL textual structures as highlighted in the above two case studies of literatures in Assamese language and be considered "translation" and not "transcreation"? To be noted here is that it was the ability to develop a methodological framework for translation (and translators) that perhaps was one of the high points of the model of semantic transference of meaning through translation, best exemplified in Nida's model of dynamic equivalence.

In this given problematic, two factors assume centrality, viz. (a) the role of translator and (b) objective of translation. The nature of translation crucially hinges on the two factors. This can be explained through an example in which Indira (Mamoni Raisom) 
Goswami herself has been involved. In the book Melodies and Guns (translation of militant/ 'secessionist' Assamese poetry into English), published in 2006 and edited by Goswami, it is stated in the introduction and discussions that followed its publication that the objective of the project was to bring to the democratic space (of public domain) literatures that are not'nationalist' in nature, yet which have emerged as significant genres in Assamese language especially since the 1990s. Since the objective was that the literature is successfully situated in the public domain, therefore the principles of non-translatability or of resistant or 'subaltern' translation were ruled out as possible frameworks. Therefore, the fundamental assumption behind the translation was that the selected poetry lies within the domain of translatability. The introduction to the volume make it amply clear that the nature of translation practiced in the book needs to be understood vis-à-vis the above assumption or objective of the work. Melodies and Guns is a case wherein the role of translator and objective of translation play a fundamental role in the translation framework or translation principle being followed. The nature of the translation can only be explained in relation to the two factors. It also highlights the fact that the given translation in Melodies and Guns cannot be taken as the only available model to translate the selected poems. If the objective of translation and the role of translator are assumed differently, the nature of translation will vary.

It is this facility that the generative approach provides which can make possible more successful translation of complex textual structures as in the cases of Bezbarua or Goswami. For example, with regard to a text like Goswami's Bhikhar Patra Bhangi (To Break the Begging Bowl), it is quite possible to argue that only one principle of translation, whether be based on culture, gender, class, nationhood or region, may be insufficient to communicate (a) the meaning of the text which encompasses all the above issues and (b) serve the presumed objective behind relating it to the context of the TL culture, since the meaning of the text lies in the interstices of the issues. Evidently, the basic issue here is not whether equivalence between SL text and TL text is arrived at 
through the translation. Rather, the issue is whether translation (of meaning) of the SL text, its interpretation and the politics behind its translation has been accommodated in the given translation available in the TL text. In other words, the question is whether the TL text accommodates the objective/ideology behind the translation successfully.

But an obvious corollary that emerges then is can one argue that any translation in that case be a valid translation? The question can be answered at two levels. Firstly, valid translation needs to be disconnected from the notion of 'good' and 'bad' translation, both 'good' and 'bad' being subjective experiential qualities. In other words, translation cannot be classified, despite Nida's dynamic equivalence, into 'good' and 'bad'. Secondly, and more importantly, validity is connected here to the three premises of translation, interpretation and its politics rather than to arriving at 'equivalence.' But the question of validity also raises another methodological question of assessment, viz. (a) is translation to be judged or (b) is translation (of the same text but differently) only to be classified into different types rather than be judged.

If it is assumed that under the rubric of generative approach to translation, the latter (i.e. translation be classified rather than be judged) is to be considered the option that can be critically accepted vis-à-vis the assessment of translation, the immediate question to emerge then is whether it slips into the post-modernist dilemma of fragmented reality. However, as discussed in Section I, classification of translation is premised on criteria, such as the objective behind translation or the role of translator, etc. Translation is a unique area of simultaneous critical intervention in theory and praxis. In this nature of intervention, the translator and his/her objective of translation play a fundamental role. Therefore, classification of translation needs to be based on the above criterion. It is this criterion that situates the translation in relation to both SL culture and TL culture and also locating the role of translation in this entire process of culture production. Further, in such an approach, the premise of validity 
of a given translation does not stand, precisely because there is no claim in the translation to any absolute translation of the SL text (as is claimed in the principle of equivalence). Thus, the mode of classification and assessment gets established.

In the light of the above discussion, one may argue that that it is only the above framework of translation that can be most fruitful vis-à-vis translation of texts written in modern Indian languages (MIL). Compared to western practices, there has been a difference in the principle of equivalence followed since the 19th century vis-à-vis translations in MIL. The difference has been that rather than SL-TL paradigm as in the West it has been primarily SL culture-TL culture paradigm in the case of MIL. The difference in the paradigm possibly emerges from one basic feature in MIL, viz. these languages share both commonality and difference at the same time with each other due to the nature of historical development of these languages since the latter part of first millennium AD. Further, in the case of most texts in MIL, the multiple language variant model (for example, the case of Goswami in Assamese literature) is widely practiced. As a result, embedded translation as a feature remains central to textual structure in most texts written in MIL. In other words, given the nature and use of MIL language in a given text, the framework of surface structure-deep structure may prove insufficient to arrive at any absolute translation. It can only remain a mythical ideal.

Studies on the history of development of languages, connected histories and delimiting the expanse of such cultural connectedness over time or space have shown that the meaning of texts often exist at the interstices of relations, both at interlingual and intra-textual levels. In this essay, few dimensions in this regard were demonstrated through Goswami's writings. However, it would be correct to argue that the case is general to most textual productions in MIL. If that be the case, wouldn't the generative translation approach be more conducive than the semantic transference approach of translation across MIL, an approach which is institutionally promoted in India? Secondly, 
if the generative approach is accepted as the one better suited to both examine and do translation in MIL, wouldn't one have to return to the question of criteria of assessment and classification of translation as more appropriate rather than judgement of translation? This possibly is an unexplored area of translation studies and praxis in South Asia, which also holds the potential of liberating text and literary culture from the institutional emphasis on "source" text and culture, and thereby allowing re-connecting to the older historical processes of cultural exchanges which lay at the heart of generation of language, genres and literary traditions. Such a possibility is of utmost importance for literary cultures in regions like North East India, especially if one is to redraw the literary map of the region where the oral and written texts had frequently intersected historically in the production of cultural meaning at both inter-lingual and intra-textual levels.

One concluding point maybe submitted here. This paper has used the illustrations from Assamese literature to make the general arguments. Given the history of development of the language and literary traditions in it (Baruah: 2012), one may therefore ask to what extent the illustration encompasses the other languages of northeast India, especially those which have generally not shared historical ties with Sanskrit in some form. Against this hypothetical question, I would argue that the point made in the paper is not about SL-TL relation, but about relation between SL-TL cultures. In fact, the argument has been that the SL-TL model of translation, borrowed from West, and which is predominant in institutional translation practices in South Asia, itself needs revision. When one moves from SL-TL paradigm to SL-TL culture paradigm, the basic contention of the paper, i.e. meanings are located at interstices of inter-lingual and intratextual relations, stands valid for languages or literary traditions in the region, whether or not they have shared historical relations with Sanskrit.

For example, the point can be illustrated through the traditions of folktales widely found in the region. A frequently 
occurring dimension in folktales across societies is that of sociocultural relations across space and society. Whether in the form of travels, of material culture or politics, folktales amply demonstrate that processes of culture and society were premised on relations rather than isolation. The moot point is that cultural forms in individual societies did not develop in isolation from one another. They were fashioned by and through these relations. If that be the case, the argument elaborated with regard to MIL stands applicable to literatures in those languages of the region, which irrespective of ties with overarching languages such as Sanskrit or Chinese or Burmese, shared relations with one another in the region. To draw linguistic affinity with Sanskrit, or Chinese or Burmese or Tibetan, etc, and to locate the problem of translation in such linguistic affinities would only be a return to the SL-TL model.

As shown in the case of Goswami's texts, linguistic affinity of modern Assamese with Sanskrit does not necessarily aid in deciphering textual meaning, and neither does it help in locating the position from which the act/choices of translation will be done by the translator. This is because of the understanding that meaning does not exist independent of the translator or the translator's context. Therefore, by shifting the focus away from languages to locating languages in the larger context of inter-cultural relations, and by emphasizing the importance of interpretation of culture in the understanding and reproduction of meanings through translation, the generative approach provides scope to explore beyond the idea of linguistic affinities between SL and TL. It allows locating inter-cultural relations at multiple levels and forms. In other words, if one method of locating Assamese could be the MIL context, another method could be its relations in the context of culture formations through Tibeto-Burman languages in the region. Therefore, the notion of linguistic affinity with languages within a "language family" may be insufficient criteria for SL-TL methodologies vis-à-vis languages such as Assamese. At this juncture, one may return to the point with which Section I was concluded, viz. the problem with the 
assumption of naturalizing the SL text in the TL text, and the methodologies developed towards it. It was the understanding of linguistic difference and the necessity to translate despite it that methodologies were developed towards the possibility of such translations. The notion of naturalizing translation hinged on it. By shifting the focus to interpretation of culture and therefore necessities of translation, the question of equivalence and its methodological implications can be meaningfully refocused towards newer forms and methods, not only of translation, but also of interpreting cultural relations across societies in northeast India. And in this regard, perhaps it would not be an exaggeration to remark that the generative approach holds the possibilities of significant experiments in theoretical and practical domains of translation in northeast India.

\section{NOTES}

1. Sarma, S.N. (ed.) 1955. Katha Ramayana. Calcutta: Sribharati Publications

2. The concept of rupture within text is different from that of split of meaning within the structure of the text. In the former, shown especially in Marxist structuralist literary criticism, the problematic is that the various elements that constitute the narrative of the text, such as language and grammar, the role of the author, characterization, or plot and its progression, do not necessarily mean the same individually as they mean as a totality. In other words, there exists an inconsistency between the individual elements and that of the total meaning that texts seek to express. The difference is overcome through the role of ideology; however close study of texts always reveals the failure of ideology to completely overcome or knit together the inconsistencies into what it seeks to express. In the case of split of meaning that is found for example in Mamoni Raisom's texts, the role of the subject matter and its arrangement into a narrative structure are already different. Therefore, ideology does not try to knit together inconsistencies of 
the individual elements. Rather, the inconsistencies get a meaning of their own in the process of split between subject matter and its arrangement into a narrative. The split is part of the larger ideological statement that author/text seeks to make. Therefore, split is not rupture. In fact, it is the means to overcome rupture. On why rupture can exist in texts, see Macherey, P. 1978. A Theory on Literary Production. London: Routledge and Kegan \& Paul.

\section{REFERENCES}

Baker, M. 1992. In Other Words: A Coursebook on Translation. London \& New York: Routledge

Baruah, Manjeet. 2012. Frontier Culture: A Social History of Assamese Literature. Delhi: Routledge.

Fitch, Brian T. 1988. Beckett and Babel: An Investigation into the Status of the Bilingual Work. U of Toronto Press: Toronto.

Gentzler, Edwin. 2010. 2001 Contemporary Translation Theories, Multilingual Matters Ltd., England

Lefevere, A. (ed) 1993. Translation/History/Culture. London: Routledge.

Nida, E. 1964. Toward a Science of Translating. Lieden: E.J. Brill.

Spivak, G. 'Translation as Culture', in Paul, St Pierre et al (ed.). 2007. In Translation-Reflections, Refractions, Transformations, pp. 263-276. Amsterdam/Philadelphia: John Benjamins Publishing Company.

Strauss, L. 1984. 'Totemism and the Savage Mind', in Anthropology \& Myth: Lectures 1951 - 1982, pp. 33. Basil Blackwell: Oxford.

Venuti, L. (ed.). 1992. Rethinking Translation: Discourse Subjectivity Ideology. London and New York: Routledge.

Venuti, L. (ed.). 2004. The Translation Studies Reader. London and New York: Routledge. 